\title{
FORMULATION AND EVALUATION OF METFORMIN HYDROCHLORIDE AND GLICLAZIDE SUSTAINED RELEASE BILAYER TABLETS: A COMBINATION THERAPY IN MANAGEMENT OF DIABETES
}

\section{RAJESWARI ALETI ${ }^{*}$, SRINIVASA RAO BARATAM ${ }^{2}$, BANGARUTHALLI JAGIRAPU ${ }^{1}$, SRAVYA KUDAMALA ${ }^{1}$}

1Department of Pharmaceutical Technology, Andhra University, Andhra Pradesh 530003, India, ${ }^{2}$ St. Ann's College of Pharmacy, Andhra University, Andhra Pradesh 530003, India

Email: razi.pharma.87@gmail.com

Received: 08 Mar 2021, Revised and Accepted: 21 Jun 2021

\section{ABSTRACT}

Objective: The main objective of the present investigation is to develop a sustained-release (SR) formulation to optimize the postprandial elevation of glucose level in type 2 Diabetic subjects using combination therapy. In the present research work, bilayer sustained release formulation of metformin hydrochloride (MFH) and gliclazide (GLZ), based on monolithic-matrix technology was developed and evaluated.

Methods: The formulations of metformin hydrochloride layer and gliclazide layer that contain polyox WSR coagulant and different viscosity grades of hydroxyl propyl methylcellulose (HPMC) as sustained-release matrix were prepared by direct compression and wet granulation method respectively. The bilayer tablets were prepared after carrying out the optimization of metformin layer and evaluated for various pre-compression and post-compression parameters. For the best formulation selected on basis of in vitro evaluation of tablets, Fourier-transform infrared spectroscopy (FT-IR) studies and comparison of in vitro dissolution profile of developed formulation with the innovator were performed.

Results: Metformin hydrochloride and gliclazide showed sustained release of drug by diffusion mechanism and followed first-order kinetics. The best formulation of metformin hydrochloride (M7) and gliclazide (G8) show $99.93 \%$ and $99.65 \%$ of drug release in 24 h respectively. The similarity factor (f2) was 79.95 for metformin hydrochloride and 73.62 for gliclazide when compared with the innovator.

Conclusion: The monolith diffusion-controlled bilayer tablets of metformin hydrochloride and gliclazide offer improved patient compliance and convenience with better postprandial hyperglycemic control with once-a-day dosing. The sustained release of the drug up to $24 \mathrm{~h}$ regulate antidiabetic activity round the clock with minimal side effects.

Keywords: Bilayer tablet, Sustained-release, Metformin hydrochloride, Gliclazide and type 2 diabetes mellitus

(C) 2021 The Authors. Published by Innovare Academic Sciences Pvt Ltd. This is an open access article under the CC BY license (https://creativecommons.org/licenses/by/4.0/) DOI: https://dx.doi.org/10.22159/ijap.2021v13i5.41339. Journal homepage: https://innovareacademics.in/journals/index.php/ijap

\section{INTRODUCTION}

Insulin is an anabolic hormone responsible for the maintenance of glucose homeostasis in the human body. It helps in the uptake of glucose molecules into the tissues and results in the utilization of glucose moiety into energy by various biochemical mechanisms [1]. However, lack of adequate insulin levels in our body leads to several chronic metabolic disturbances of carbohydrate, fat, and protein that is often termed as diabetes mellitus (DM) which is a serious and lifelong condition [2]. There are two principal forms of diabetes: type 1 diabetes, in which the pancreas fails to produce insulin, and type 2 diabetes, which results from the body's inability to respond properly to the action of insulin produced by the pancreas [3]. The prevalence of diabetes has increased globally over the years and it has been noted as one of the leading causes of high mortality and morbidity rate [4]. About 422 million people worldwide have diabetes and 1.6 million deaths are directly attributed to diabetes each year [5]. According to the IDF statistics, adults with type 2 diabetes (T2 DM) outnumber those with type 1 diabetes [6]. Type 2 DM is a heterogeneous disorder characterized by multiple problems in the pancreatic $\beta$-cell, liver, and peripheral tissue such as skeletal muscles and adipose tissue. These multiple complications are well managed by combination therapy using two antidiabetic drugs. Combination therapy is more advantageous than monotherapy in minimizing problems such as dose-dependent side effects, dosing frequency, etc. A low-dose combination of two different drugs reduces dose-related risks and minimizes the clinical and metabolic side effects that occur with the maximal dosage of individual components as in monotherapy, and thus dosage of the single components can be reduced [7, 8]. Diabetes needs much attention as glucose levels that tend to increase after a meal, have to maintain for the whole day for proper activity of the body [9]. To combat such conditions, sustained-release (SR) formulations that regulate antidiabetic activity round the clock need to develop to optimize the postprandial elevation of glucose levels [10].
Metformin hydrochloride, an oral biguanide first-line choice of drug and gliclazide (GLZ), the second-generation sulphonylurea provides good hypoglycemic excellence by increasing both basal and mealstimulated insulin secretion along with enhancement of peripheral insulin sensitivity, ultimately leading to declining in fasting, postprandial glucose, and glycosylated hemoglobin (HbA1c) levels [11]. Bilayer technology is one of the suitable approaches for the successful development of sustained-release formulations that provide a way of successful drug delivery. A bi-layer tablet is suitable for the fabrication of sustained release dosage form (tablet) consisting of two drugs in combination in two different layers and sequentially release the drugs [12]. The present research aimed to develop a sustained release bilayer formulation using combination therapy, which provides better postprandial hyperglycemic control with a daylong duration and reduces the economic burden in management of diabetes compared to the expenses in marketing new drug entities. The objective of the present investigation is to design and evaluate sustained release bilayer tablets containing metformin hydrochloride and gliclazide.

\section{MATERIALS AND METHODS}

\section{Materials}

Metformin hydrochloride and gliclazide were supplied as a gift sample from Cipla Pharmaceuticals Ltd., Mumbai. Desai chemicals Ltd remained as a main supplier for the polyox WSR coagulant, HPMC polymers of grade K4M, K15M, K100M and all other excipients used in the study. HPLC grade acetonitrile, potassium dihydrogen phosphate, orthophosphoric acid AR grade purchased from Lotus Chem. Mumbai, India. Waters e 2695 separation module with high pressure liquid chromatographic instrument provided with an RP-Select B C18 column $(250 \mathrm{~mm} \times 4.6 \mathrm{~mm} ; 5 \mu)$ and 2489 UV-Visible detector, auto-injector, an autosampler with Empower 2 software from Waters Corporation, Milford USA was employed in the study. 


\section{Methods}

\section{Experimental method}

\section{Drug-excipient interaction study}

It is a critical primary concern for any dosage form to study the compatibility of drug, polymer and other excipients; therefore, it is necessary to confirm that the drug does not interact with polymers and excipients under experimental conditions and affects the shelf life of the product. The drug excipient compatibility has done by physical observation of mixtures for one month and FT-IR study. The drug has mixed with excipients in a different ratio. These mixtures were kept in $5 \mathrm{ml}$ glass white-colored vials and packed properly. These vials were exposed to room temperature and $40^{\circ} \mathrm{C} / 75 \%$ RH. 2 to $3 \mathrm{~g}$ of the blend was prepared and filled in three vials. Observations for any physical change in appearance were performed at zero weeks to one month [13]

\section{FTIR spectroscopy}

Fourier transform infrared spectroscopy (FT-IR) investigations were used to detect possible drug-drug and drug-excipient interactions by using an FT-IR spectrometer-430 (Jasco-Japan). The Potassium Bromide pellets, an infrared transparent matrix, were prepared on $\mathrm{KBr}$ press on grounding the solid powder sample with 100 times the quantity of $\mathrm{KBr}$ in a mortar [14]. The spectra were recorded at a resolution of $4 \mathrm{~cm}^{-1}$ over the wavenumber of 4000 to $400 / \mathrm{cm}$.

\section{Analytical method}

Preparation of stock and working standard solution of metformin hydrochloride and gliclazide

A mixture of $\mathrm{pH} 6.6$ phosphate buffer and acetonitrile in the ratio $60: 40 \% \mathrm{v} / \mathrm{v}$ filtered through $0.45 \mu$ membrane filter used as mobile phase for preparing the working solution of the drug. About $500 \mathrm{mg}$ of metformin hydrochloride and $60 \mathrm{mg}$ of gliclazide were accurately weighed and transferred into a $100 \mathrm{ml}$ volumetric flask, the solution was sonicated and the resulting solution was diluted with the mobile phase to obtain a primary stock solution. $10 \mathrm{ml}$ of this stock solution was further diluted to $100 \mathrm{ml}$ using mobile phase to obtain $500 \mu \mathrm{g} / \mathrm{ml}$ metformin hydrochloride and $60 \mu \mathrm{g} / \mathrm{ml}$ gliclazide. From this solution, suitable working solutions of different concentrations were prepared.

\section{Construction of calibration curve of metformin hydrochloride and gliclazide}

Linearity of the peak area response was determined by measuring working standard dilution of metformin hydrochloride and gliclazide in the range of $125-750 \mu \mathrm{g} / \mathrm{ml}$ and $20-120 \mu \mathrm{g} / \mathrm{ml}$ respectively. Triplicate of the $20-\mu$ l quantity of each dilution injected each time into the column. The drug in elutes was monitored at $261 \mathrm{~nm}$ and the corresponding chromatograms were obtained. From these chromatograms, a plot of amount and response was constructed. The regression equation (fig. 1 and 2) obtained was used to estimate the amount of drugs present in a pharmaceutical dosage form.

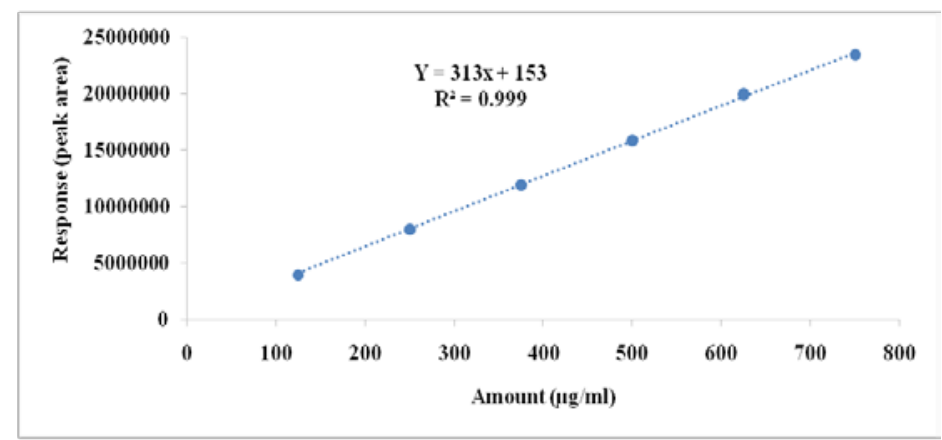

Fig. 1: Calibration curve of metformin hydrochloride

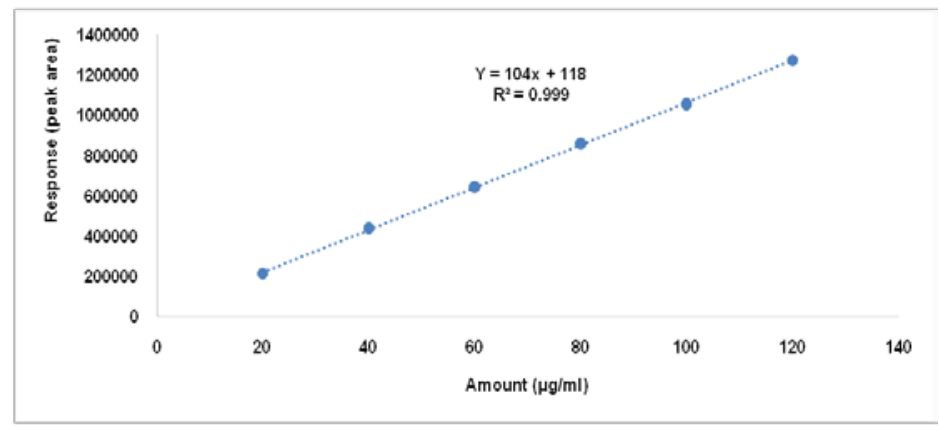

Fig. 2: Calibration curve of gliclazide

\section{Formulation development of bilayer tablets}

Development of bilayer tablets of metformin hydrochloride and gliclazide was carried out in two stages. Blends of the SR layer of metformin hydrochloride (layer 1) and gliclazide (layer 2) were prepared and initially compressed separately for preliminary evaluations. After optimization of an individual layer, the bilayer tablet was prepared using selected formulas.

\section{Formulation of metformin hydrochloride layer (layer-1)}

Metformin hydrochloride is a very moisture-sensitive drug. Hence, various formulations of metformin hydrochloride were prepared by non-aqueous wet granulation (M1-M4) and direct compression (M5-
M7). In formulations, (M1-M4) HPMC K100M was used as a retardant. All the ingredients passed through a 60-mesh sieve. A blend of all ingredients was mixed thoroughly in a rapid mixer granulator resulting in phase homogenization and granulated manually with a binder solution, which was prepared by dissolving povidone $\mathrm{K} 30$ in isopropyl alcohol. The wet masses were passed through a 12 mesh sieve and the wet granules produced was initially air-dried for $10 \mathrm{~min}$ and finally at $45-50{ }^{\circ} \mathrm{C}$ in a tray dryer for $2 \mathrm{~h}$ until the LOD (Loss on drying) of granules reached moisture limit between $2-3 \% \mathrm{w} / \mathrm{w}$. The dried granules sieved by 16 mesh sieve were lubricated with magnesium stearate (which was sifted through 60 mesh) and compressed to tablets. Formulations (F5-F7) were prepared using polyox WSR coagulant as retardant along with other 
excipients. The ingredients passed through a 60 -mesh sieve, mixed thoroughly in a rapid mixer granulator, lubricated and compressed. Before compression, the final blend was evaluated for its flow and compressibility characteristics. All the tablets compressed using Cadmach single punch tablet compression machine with $12 \mathrm{~mm}$ concave punch were stored in airtight containers for further study $[15,16]$. The composition of the metformin hydrochloride sustained release layer is mentioned in table 1.

\section{Formulation of gliclazide layer (layer-2)}

Various formulations of gliclazide (G1-G9) were prepared with different ratios of Hydroxy Propyl Methyl Cellulose of different grades like HPMCK4M, HPMC-K15M, HPMC-K100M and other ingredients by taking appropriate quantities as mentioned in table 2 . The granules were prepared by the wet granulation method. The ingredients passed through a 60-mesh sieve. A blend of all ingredients except glidant and lubricant mixed thoroughly in a rapid mixer granulator resulting in phase homogenization and granulated manually with a binder solution prepared by dissolving povidone K30 in isopropyl alcohol. The wet masses were passed through a 12 mesh sieve and the wet granules produced was initially air-dried for $10 \mathrm{~min}$ and finally at $45-50^{\circ}$ in a tray dryer for $2 \mathrm{~h}$ until the LOD (Loss on drying) of granules reached moisture limit between $2-3 \% \mathrm{w} / \mathrm{w}$. The dried granules sieved by a 16 mesh sieve were lubricated with magnesium stearate (which was sifted through 60 mesh) and compressed to tablets. Before compression, the granules were evaluated for pre-compression parameters. The composition of the gliclazide layer is mentioned in table 2 .

\section{Characterization of the powder blend}

Precompression parameters of the metformin hydrochloride and gliclazide powder blends such as angle of repose, bulk density, tapped density, Carr's index, and Hausner's ratio were determined for their micromeritic properties before compression of the tablet were mentioned in table 3 and 4 respectively.

Table 1: Composition of metformin hydrochloride layer

\begin{tabular}{|c|c|c|c|c|c|c|c|}
\hline \multirow[t]{2}{*}{ Ingredients (mg) } & \multicolumn{7}{|c|}{ Formulation code } \\
\hline & M1 & M2 & M3 & M4 & M5 & M6 & M7 \\
\hline Metformin hydrochloride & 500 & 500 & 500 & 500 & 500 & 500 & 500 \\
\hline HPMC K100M & 120 & 160 & 200 & 240 & - & - & - \\
\hline PolyoxWSR coagulant & - & - & - & - & 160 & 220 & 210 \\
\hline MCC & 140 & 100 & 60 & 20 & - & - & - \\
\hline Mannitol & - & - & - & - & 95 & 35 & 45 \\
\hline PVP K 30 & 25 & 25 & 25 & 25 & 25 & 25 & 25 \\
\hline IPA & qs & qs & qs & qs & qs & qs & qs \\
\hline
\end{tabular}

HPMC: Hydroxypropylmethylcellulose, MCC: Microcrystalline cellulose, PVP: Polyvinyl pyrrolidone, IPA: Isopropyl alcohol, qs: quantity sufficient. Total weight per tablet: $800 \mathrm{mg}$

Table 2: Composition of gliclazide layer

\begin{tabular}{|c|c|c|c|c|c|c|c|c|}
\hline \multirow[t]{2}{*}{ Ingredients (mg) } & \multicolumn{8}{|c|}{ Formulation code } \\
\hline & G1 & G2 & G3 & G4 & G5 & G6 & G7 & G8 \\
\hline Gliclazide & 60 & 60 & 60 & 60 & 60 & 60 & 60 & 60 \\
\hline DCP & 90 & 70 & 50 & 90 & 80 & 70 & 90 & 80 \\
\hline HPMC K4M & 20 & 30 & 40 & - & - & - & - & - \\
\hline HPMC K15M & - & - & & 20 & 30 & 40 & - & - \\
\hline HPMC K100M & - & - & - & - & - & - & 20 & 30 \\
\hline PVP K30 & 6 & 6 & 6 & 6 & 6 & 6 & 6 & 6 \\
\hline Iron oxide yellow & 0.5 & 0.5 & 0.5 & 0.5 & 0.5 & 0.5 & 0.5 & 0.5 \\
\hline SA & 20 & 20 & 20 & 20 & 20 & 20 & 20 & 20 \\
\hline IPA & qs & qs & qs & Qs & qs & qs & qs & qs \\
\hline Magnesium stearate & 4 & 4 & 4 & 4 & 4 & 4 & 4 & 4 \\
\hline
\end{tabular}

DCP: Dicalcium phosphate, HPMC: Hydroxy Propyl Methyl Cellulose, PVP: Polyvinyl pyrrolidone, IPA: Isopropyl alcohol, SA: Sodium alginate, qs: quantity sufficient. Total weight per tablet: $200 \mathrm{mg}$

\section{Evaluation of marketed formulation exermet GZ 560}

The marketed product (Exermet GZ 560) was evaluated to determine thickness, weight and dissolution profile following the standard method of testing. The values of these properties are given in table 5 .

\section{Evaluation of post-compression parameters}

\section{Physicochemical properties of tablets}

The compressed monolithic matrix tablets are characterized for postcompression properties like weight variation, friability, hardness and thickness as per IP and USP standard methods. The weight variation of the tablets was carried out with 20 tablets using an electronic balance (Shimadzu, Japan). Friability was determined using 10 tablets in a Roche friabilator (Pharma Lab, Ahmadabad, India) for $4 \mathrm{~min}$ at 25 rpm. For each formulation, the hardness of 10 tablets was evaluated using a hardness tester (Monsanto hardness tester). The thickness of 10 tablets was measured using Vernier Calipers $[17,18]$.

\section{Drug content uniformity}

Twenty tablets weighed accurately and finely powdered. The powder equivalent to $500 \mathrm{mg}$ of metformin hydrochloride and 60 mg of gliclazide was transferred into a $100 \mathrm{ml}$ volumetric flask. 50 $\mathrm{ml}$ of $\mathrm{pH} 7.4$ buffer was added to the powder and sonicated to dissolve completely. Then the volume made up to $100 \mathrm{ml}$ with buffer and filtered by Whatman filter paper. $1 \mathrm{ml}$ of filtered solution was withdrawn and diluted to $100 \mathrm{ml}$ using the buffer. The Peak area of the sample solution was measured at $261 \mathrm{~nm}$ to calculate the concentration of the drug in the sample [19].

\section{In vitro dissolution profiles}

The marketed and manufactured formulations were tested for in vitro drug release using USP Type II paddle dissolution apparatus (LAB INDIA 8000+). One matrix tablet was placed in each flask of the dissolution apparatus and dissolution was conducted for $24 \mathrm{~h}$ at 50 $\mathrm{rpm}$ at $37 \pm 0.5^{\circ} \mathrm{C}$. Initially, the study was performed in $900 \mathrm{ml}$ of 0.1 $\mathrm{N} \mathrm{HCI}$ for $2 \mathrm{~h}$ followed by $900 \mathrm{ml}$ of pH 7.4 phosphate buffer $5 \mathrm{ml}$ of sample was withdrawn at time intervals $2,4,6,8,10,12,16$ and 24 $\mathrm{h}$ and the same volume was replaced to maintain sink conditions [20-21]. During sampling, samples were filtered through Whatman filter paper, suitably filtered and analyzed by the reported HPLC method at $261 \mathrm{~nm}$ using standard stocks. Each sample was injected six times and the sample retention times were observed in all cases. Retention time about 3.27 min for metformin hydrochloride and $6.12 \mathrm{~min}$ for gliclazide observed for stock solution. 


\section{Dissolution data analysis}

The dissolution profile comparison carried out using the modelindependent or model-dependent method. A simple modelindependent approach uses a difference factor $\left(f_{1}\right)$ and a similarity factor $\left(f_{2}\right)$ to compare dissolution profiles.

$$
\begin{gathered}
f 1=\left\{\left[\sum_{\mathrm{t}=1^{\mathrm{n}}}\left|\mathrm{R}_{\mathrm{t}}-\mathrm{T}_{\mathrm{t}}\right|\right] /\left[\sum_{\left.\left.\mathrm{t}=1^{\mathrm{n}} \mathrm{R}_{\mathrm{t}}\right]\right\} \times 100}\right.\right. \\
f 2=50 \times \log \left\{\left[1+(1 / n) \sum \mathrm{t}=1^{\mathrm{n}}\left(\mathrm{R}_{\mathrm{t}-} \mathrm{T}_{\mathrm{t}}\right)^{2}\right]^{-0.5} \times 100\right\}
\end{gathered}
$$

Where, $R_{t}$ and $T_{t}$ represent the average percent dissolved at time $t$ for reference and test, respectively and $n$ is the number of time points tested.

Dissolution profile considered satisfactory if $f 1$ values lie below 50 (nearing zero) and $f 2$ values lie more than 50 (nearing 100). If the $f 2$ value is between 50-100, the value of the test and the reference are identical. The model-independent method is most suitable for dissolution profile comparison when three to four or more dissolution time points are available [23].

\section{Kinetic model fitting}

Dissolution data of the above two methods were fitted in Zero order, First order and Higuchi equations. Based on the slope and $\mathrm{r}^{2}$ values obtained, the mechanism of drug release was determined.

\section{Accelerated stability studies}

The accelerated stability testing was conducted to provide evidence on how the quality of a drug substance varies with time under influence of a variety of environmental factors such as temperature, humidity, light and enables recommended storage conditions. The study was conducted by wrapping the bilayer tablets in aluminum foils and kept at $25{ }^{\circ} \mathrm{C} / 60 \% \mathrm{RH}$ and $40{ }^{\circ} \mathrm{C} / 75 \% \mathrm{RH}$. Then the tablets were checked for appearance, thickness, and hardness. In addition, drug content and dissolution studies were performed periodically for 6 mo and compared with initials as per ICH guidelines [26].

\section{RESULTS AND DISCUSSION}

\section{Drug-excipient interaction study}

The compatibility of the pure drug with its excipients on physical observation exhibited no interaction; therefore, the excipients were selected for formulation. The distinctive melting points were observed for metformin hydrochloride at $224^{\circ} \mathrm{C}$ and gliclazide at $182{ }^{\circ} \mathrm{C}$ and no evident melting point changes were noted indicating overall compatibility.

\section{FT-IR spectroscopy}

The FT-IR spectrum of metformin hydrochloride and gliclazide in formulations was as shown in fig. 3C. FT-IR studies revealed that metformin hydrochloride showed two typical bands at 3371 and $3296 / \mathrm{cm}$ due to $\mathrm{N}-\mathrm{H}$ primary stretching vibrations and a band at $3174 / \mathrm{cm}$ due to $\mathrm{N}-\mathrm{H}$ secondary stretching, and characteristics bands at 624 and $1584 / \mathrm{cm}$ assigned to $\mathrm{C}=\mathrm{N}$ stretching. No significant shifts of reduction in the intensity of the FT-IR bands of metformin hydrochloride were observed which indicates the absence of drugdrug interaction and drug-polymer interaction between metformin hydrochloride and Polyox WSR coagulant.

Hence, these two drugs were selected for the development of sustained-release bilayer tablets and polyox WSR coagulant was selected as a release-retarding agent. An IR spectrum of pure gliclazide shows two characteristic peaks. A peak at $3414.85 \mathrm{~cm}^{-1}$ due to $\mathrm{NH}$ group and another peak at $1636.79 \mathrm{~cm}^{-1}$ due to $\mathrm{C}=0$ as observed in fig. 3B showing no interaction indicating overall compatibility with the polymer HPMC K100M and excipients.

\section{Characterization of powder blend}

The results of the pre compressional parameters such as bulk density, tapped density angle of repose, Hausner's ratio and compressibility index of all batches of SR blend containing metformin hydrochloride and gliclazide exhibited good characteristics. All the formulations showed good compressibility and flow properties than pure drugs. The precompression values of metformin hydrochloride and gliclazide blend were indicated in table 3 and table 4 respectively.

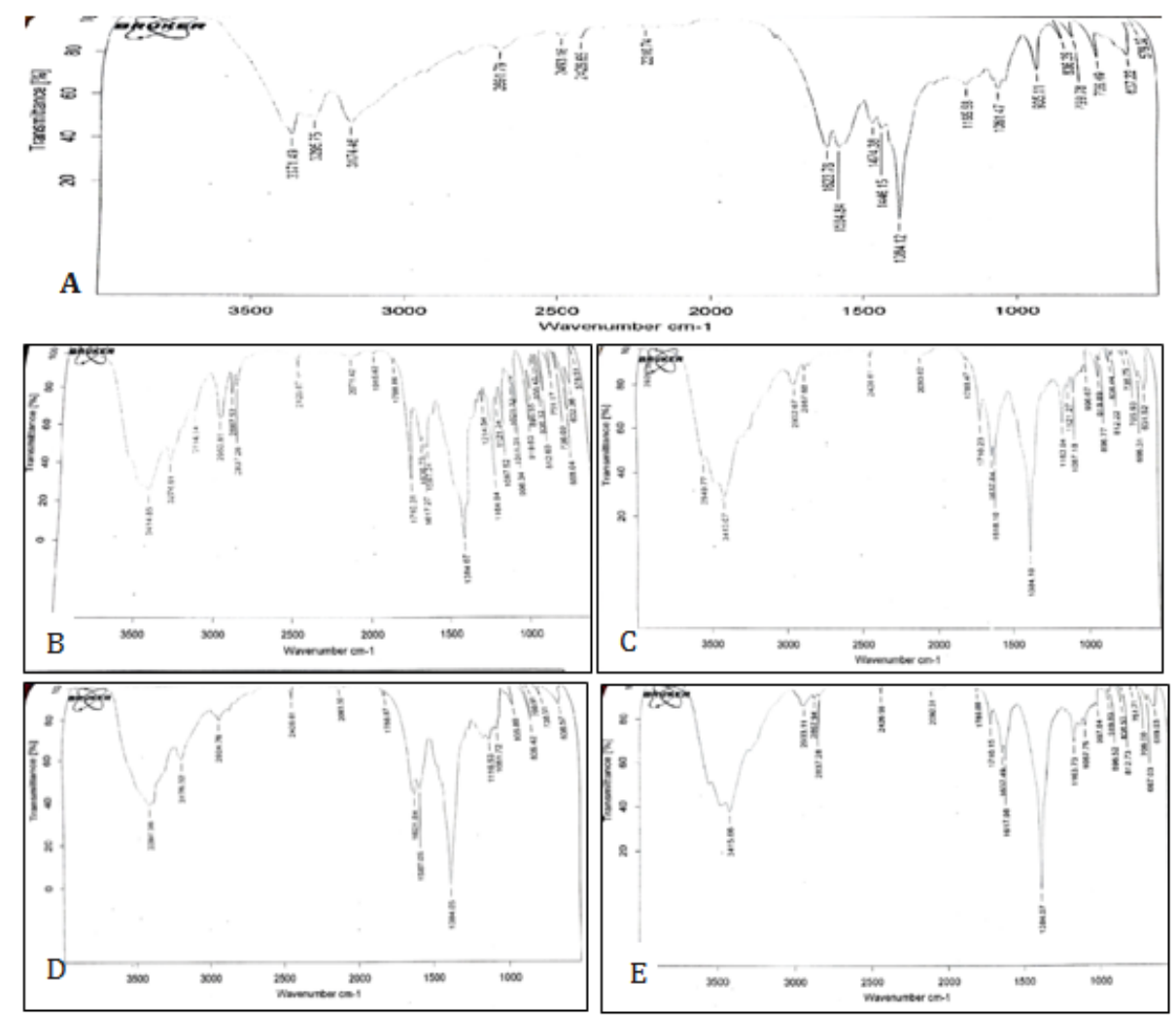

Fig. 3: Fourier transform infrared spectrum (A) Metformin hydrochloride (B) Gliclazide (C) Metformin hydrochloride+Gliclazide (D) Metformin hydrochloride+Polyox WSR coagulant (E) Gliclazide+HPMC K 100M 
Table 3: Precompression parameters of metformin hydrochloride formulation M1-M7

\begin{tabular}{|c|c|c|c|c|c|}
\hline Formulation code & Bulk density $\left(\mathrm{g} / \mathrm{cm}^{3}\right)$ & Tapped density $\left(\mathrm{g} / \mathrm{cm}^{3}\right)$ & Compressibility (\%) & Hausner's ratio & Angle of repose $\left({ }^{\circ}\right)$ \\
\hline M1 & $0.62 \pm 0.009$ & $0.71 \pm 0.038$ & 12.8 & 1.14 & 23 \\
\hline M2 & $0.72 \pm 0.012$ & $0.85 \pm 0.0983$ & 15.8 & 1.18 & 25 \\
\hline M3 & $0.68 \pm 0.018$ & $0.78 \pm 0.027$ & 13 & 1.14 & 25 \\
\hline M4 & $0.62 \pm 0.06$ & $0.74 \pm 0.012$ & 16.5 & 1.19 & 22 \\
\hline M5 & $0.61 \pm 0.053$ & $0.79 \pm 0.042$ & 22.2 & 1.28 & 28 \\
\hline M6 & $0.62 \pm 0.038$ & $0.72 \pm 0.082$ & 13.7 & 1.15 & 20 \\
\hline M7 & $0.66 \pm 0.039$ & $0.72 \pm 0.013$ & 9.14 & 1.1 & 18 \\
\hline
\end{tabular}

mean $\pm \mathrm{SD}, \mathrm{n}=3 \mathrm{SD}=$ Standard deviation

Table 4: Pre compression parameters of gliclazide formulation G1-G8

\begin{tabular}{|c|c|c|c|c|c|}
\hline Formulation code & Bulk density $\left(\mathrm{g} / \mathrm{cm}^{3}\right)$ & Tapped density $\left(\mathrm{g} / \mathrm{cm}^{3}\right)$ & Compressibility (\%) & Hausner's ratio & Angle of repose $\left({ }^{\circ}\right)$ \\
\hline G1 & $0.65 \pm 0.072$ & $0.79 \pm 0.082$ & 17.6 & 1.21 & 20.6 \\
\hline G2 & $0.54 \pm 0.012$ & $0.69 \pm 0.032$ & 22 & 1.28 & 21.7 \\
\hline G3 & $0.57 \pm 0.019$ & $0.71 \pm 0.015$ & 19.6 & 1.24 & 19.7 \\
\hline G4 & $0.52 \pm 0.062$ & $0.68 \pm 0.082$ & 22.4 & 1.29 & 19.3 \\
\hline G5 & $0.53 \pm 0.083$ & $0.68 \pm 0.029$ & 22.5 & 1.29 & 22.6 \\
\hline G6 & $0.54 \pm 0.022$ & $0.65 \pm 0.072$ & 16.3 & 1.29 & 20.1 \\
\hline G7 & $0.56 \pm 0.014$ & $0.69 \pm 0.012$ & 19.8 & 1.24 & 18.7 \\
\hline G8 & $0.52 \pm 0.092$ & $0.68 \pm 0.062$ & 22.4 & 1.29 & 19.8 \\
\hline
\end{tabular}

mean $\pm \mathrm{SD}, \mathrm{n}=3$

Table 5: Physical evaluation of the innovator

\begin{tabular}{|c|c|}
\hline Brand name & Exermet GZ 560 \\
\hline Manufacturer & Cipla \\
\hline Composition & $\begin{array}{l}\text { Metformin hydrochloride-500 mg } \\
\text { Gliclazide- } 60 \mathrm{mg}\end{array}$ \\
\hline Total weight of the tablet & $1000 \mathrm{mg}$ \\
\hline Thickness & $5.3 \mathrm{~mm}$ \\
\hline Drug content & $\begin{array}{l}\text { Metformin hydrochloride-99.97 } \pm 0.11 \% \\
\text { Gliclazide } 99.96 \pm 0.41 \%\end{array}$ \\
\hline
\end{tabular}

\section{Evaluation of post-compression parameters of tablets}

All tablets appeared smooth and oblong. The weight of the metformin hydrochloride layer was kept constant to $800 \mathrm{mg}$. All tablet batches qualify the tablet weight variation test and found variation $100 \pm 5 \%$ within range; friability below 1\%; drug content
$90-110 \%$ within limit and deviation in thickness found less than $5 \%$. Results of post-compression parameters of metformin hydrochloride tablets were observed in table 6 . The optimized metformin hydrochloride formulation was further used to prepare bilayer tablets using different gliclazide formulations. Results of post-compression parameters of bilayer tablets were observed in table 7.

Table 6: Post compression parameters of metformin hydrochloride formulations M1-M7

\begin{tabular}{|c|c|c|c|c|c|}
\hline Formulation code & Weight variation (mg) & Hardness $\left(\mathrm{Kg} / \mathrm{Cm}^{2}\right)$ & Thickness (mm) & Friability (\%) & Content uniformity \% (layer 1 ) \\
\hline M1 & $800 \pm 0.19$ & $7.5 \pm 0.23$ & $5.1 \pm 0.21$ & $0.41 \pm 0.002$ & $99.28 \pm 0.57$ \\
\hline M2 & $800 \pm 0.38$ & $7.8 \pm 0.24$ & $5.02 \pm 0.15$ & $0.68 \pm 0.005$ & $99.57 \pm 0.86$ \\
\hline M3 & $800 \pm 0.79$ & $8.5 \pm 0.23$ & $5.04 \pm 0.23$ & $0.53 \pm 0.005$ & $99.75 \pm 0.36$ \\
\hline M4 & $800 \pm 0.74$ & $8.9 \pm 0.26$ & $5.08 \pm 0.42$ & $0.36 \pm 0.008$ & $99.78 \pm 0.87$ \\
\hline M5 & $800 \pm 0.56$ & $8.3 \pm 0.93$ & $5.11 \pm 0.33$ & $0.86 \pm 0.002$ & $98.68 \pm 0.28$ \\
\hline M6 & $800 \pm 0.49$ & $8.5 \pm 0.27$ & $5.04 \pm 0.13$ & $0.72 \pm 0.004$ & $99.83 \pm 0.39$ \\
\hline M7 & $800 \pm 0.68$ & $8.4 \pm 0.23$ & $5.03 \pm 0.26$ & $0.93 \pm 0.007$ & $99.95 \pm 0.26$ \\
\hline
\end{tabular}

mean $\pm \mathrm{SD}, \mathrm{n}=3$

Table 7: Post compression parameters of gliclazide formulation G1-G8

\begin{tabular}{|c|c|c|c|c|c|}
\hline Formulation code & Weight variation (mg) & Hardness $\left(\mathrm{Kg} / \mathrm{Cm}^{2}\right)$ & Thickness (mm) & Friability (\%) & Content uniformity (\%) (Layer 2) \\
\hline G1 & $200 \pm 0.67$ & $7.5 \pm 0.23$ & $2.11 \pm 0.03$ & $0.54 \pm 0.0098$ & $98.5 \pm 0.83$ \\
\hline G2 & $200 \pm 0.29$ & $6.7 \pm 0.28$ & $2.01 \pm 0.83$ & $0.67 \pm 0.0021$ & $99.4 \pm 0.75$ \\
\hline G3 & $200 \pm 0.57$ & $7.4 \pm 0.83$ & $2.13 \pm 0.12$ & $0.49 \pm 0.0024$ & $99.3 \pm 0.62$ \\
\hline G4 & $200 \pm 0.75$ & $8.5 \pm 0.26$ & $2.17 \pm 0.08$ & $0.81 \pm 0.0027$ & $99.7 \pm 0.69$ \\
\hline G5 & $200 \pm 0.38$ & $8.5 \pm 0.73$ & $2.04 \pm 0.42$ & $0.32 \pm 0.0037$ & $99.5 \pm 0.62$ \\
\hline G6 & $200 \pm 0.32$ & $8.8 \pm 0.27$ & $2.08 \pm 0.16$ & $0.65 \pm 0.0073$ & $98.6 \pm 1.04$ \\
\hline G7 & $200 \pm 0.61$ & $8.5 \pm 0.74$ & $2.04 \pm 0.28$ & $0.87 \pm 0.0028$ & $98.6 \pm 1.67$ \\
\hline G8 & $200 \pm 0.85$ & $8.6 \pm 0.51$ & $2.03 \pm 0.34$ & $0.62 \pm 0.0065$ & $99.7 \pm 0.19$ \\
\hline
\end{tabular}

mean $\pm S D, n=3$ 
In vitro dissolution studies of the sustained-release layer containing metformin hydrochloride

All the formulations subjected to in vitro dissolution studies revealed that tablets containing release modifiers exhibited sustained release of metformin hydrochloride and gliclazide. The dissolution profile of formulations containing metformin hydrochloride was represented in fig. 4. The dissolution profile of metformin hydrochloride formulation revealed that M1-M3 formulations released the drug completely by the end of $12 \mathrm{~h}$, which is probably due to faster dissolution of the highly water-soluble drug from the core and its diffusion out of the matrix forming the pores for the entry of solvent molecules. A suitable sustained-release formulation should release the required amount of drug in the initial hour, followed by slow release. Formulation M4 (30\% HPMC K100M) exhibited the slowest dissolution profile which was consistent with USP specification. In contrast, the release of metformin hydrochloride from formulation M5-M7 prepared using polyox WSR coagulant was extended up to $24 \mathrm{~h}$. Batch M7 prepared by direct compression method using polyox WSR coagulant $(25 \%)$ exhibited a good drug release profile. Data of comparison of formulations M4 and M7 with innovator by similarity and dissimilarity factor represented in table 8 reveals that M7 is the promising batch and selected as the best formulation for further studies.

Table 8: Comparision of formulations with innovator by similarity and dissimilarity factor

\begin{tabular}{llll}
\hline Formulation & $\boldsymbol{f}_{2}$ value & $\boldsymbol{f}_{\mathbf{1}}$ value & 3.6 \\
M4 & 72.05 & 7.95 & 2.36 \\
M7 & 79.95 & \\
\hline
\end{tabular}

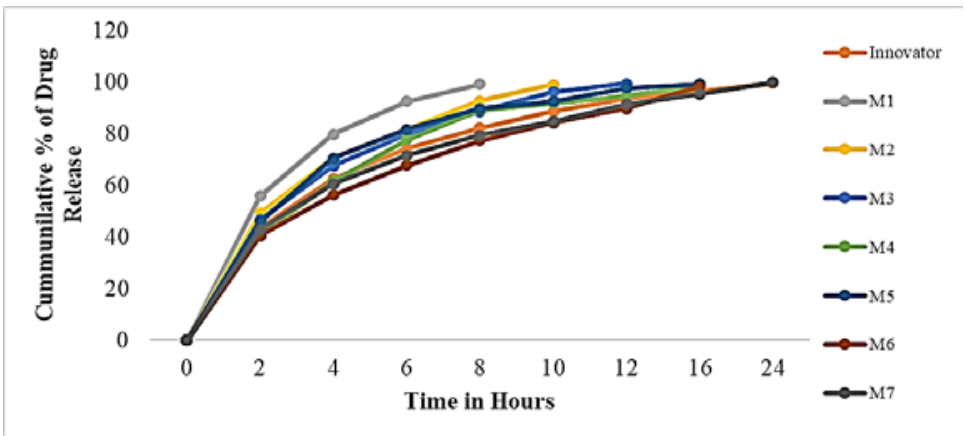

Fig. 4: In vitro dissolution profile of Metformin hydrochloride formulation M1-M7 and innovator

\section{Sustained-release layer containing gliclazide}

The dissolution profile of gliclazide formulations was represented in fig. 5. Formulation G3 and G6 displayed a cumulative release of nearly $98.7 \%$ and $99.6 \%$ in $12 \mathrm{~h}$ and $16 \mathrm{~h}$ respectively where $40 \%$ of polymers HPMC K4M and K15M were employed. In contrast, the formulation G8 exhibited a better-controlled release profile of $99.8 \%$ at $24 \mathrm{~h}$ as represented in fig. 5 .

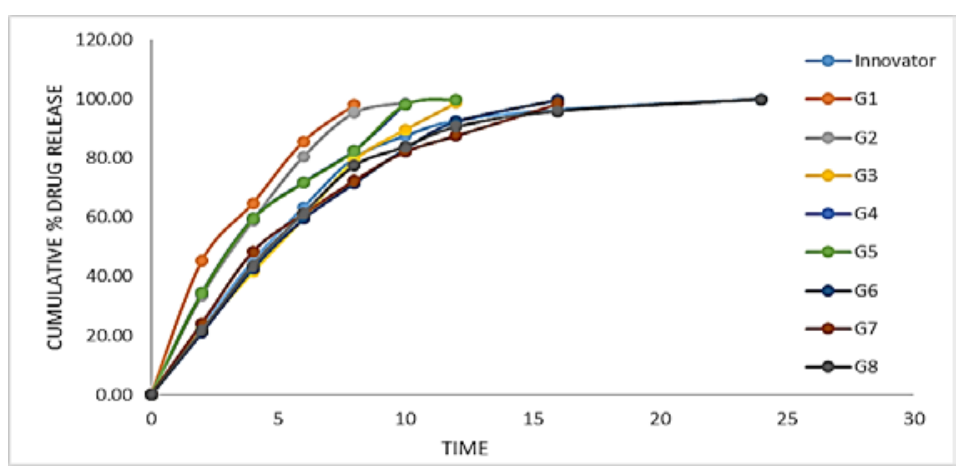

Fig. 5: In vitro dissolution profile of gliclazide formulation G1-G8 and Innovator

Here, the polymer HPMC K100M showed a better rate of retardant ability than the above two variants at a lesser concentration. The hydration rate of HPMC increases with an increase in the Hydroxyl Propyl content and the solubility of HPMC is pH-independent [22]. The water-repelling property of higher variants of HPMC retarded the drug release from the matrix by preventing the penetration of solvent molecules. HPMC K100M was judiciously selected in preparation due to its profound ability to form a strong viscous gel on contact with aqueous media, which helps in controlling the delivery of highly water-soluble drugs [24].

\section{Final compression of bilayer tablets}

Based on results of in vitro dissolution studies batch M7 of metformin hydrochloride and batch G8 of gliclazide were selected to prepare bilayer tablets. Initially, the metformin hydrochloride blend was poured into the die cavity and compressed with moderate force. Then the upper punch was lifted and the gliclazide granules were poured in the die cavity, containing initially compressed layer 1 and compressed with full force to form a bilayer tablet of $1000 \mathrm{mg}$ with a hardness of $7-8 \mathrm{Kg} / \mathrm{Cm}^{2}$ using Cadmach single punch compression machine with $12 \mathrm{~mm}$ concave punch and die [26]. The dissolution profiles of the individual layer in the final formulation were compared with the innovator (Exermet GZ 560) and results were represented in fig. 6 . From the graphs, it is evident bilayer tablet shows a similar release pattern as Exermet GZ 560 with a good similarity factor 79.95 and 73.62 for metformin hydrochloride and gliclazide respectively. The post-compression parameters of the bilayer tablets were found to be within the limits. 


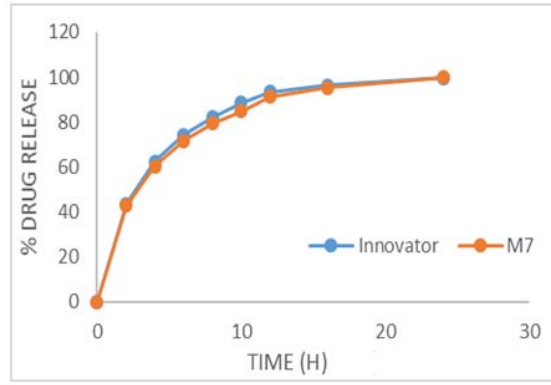

(a)

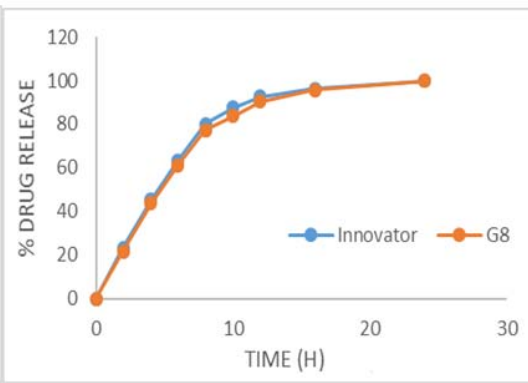

(b)

Fig. 6: Comparison of dissolution profiles of (a) Metformin hydrochloride in formulation M7 and Innovator. (b) Gliclazide in formulation G8 and innovator

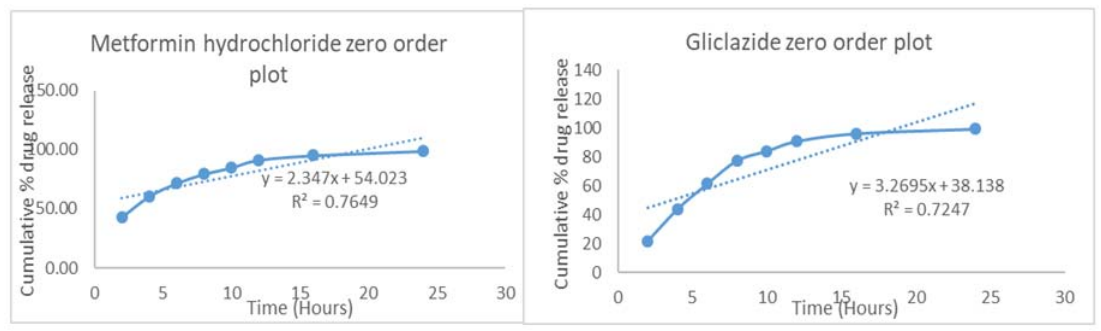

Fig. 7: Zero-order plot of drug release in an optimized bilayer tablet

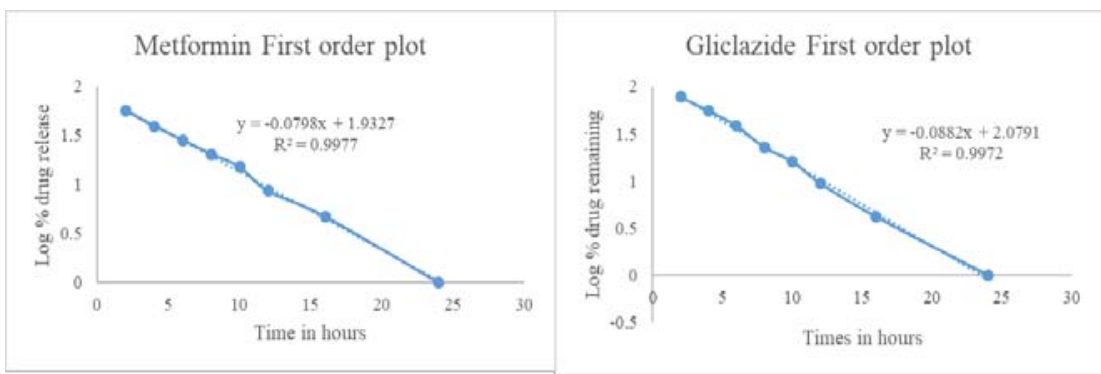

Fig. 8: First Order plot of drug release in an optimized bilayer tablet

\section{Drug release kinetics}

The release mechanism of metformin hydrochloride and gliclazide from bilayered optimized formulation was studied by fitting the data obtained from in vitro release studies into zero-order, first-order, Higuchi and Korsmeyer-Peppas models.
It is evident from fig. 8 that a linear relationship was obtained with ' $r$ ' value close to unity and higher than ' $r$ ' obtained from the zeroorder equation for optimized bilayer formulation of metformin hydrochloride and gliclazide, showing that the release is an apparent first-order process. This indicates that the amount of drug released is dependent on the matrix drug load.
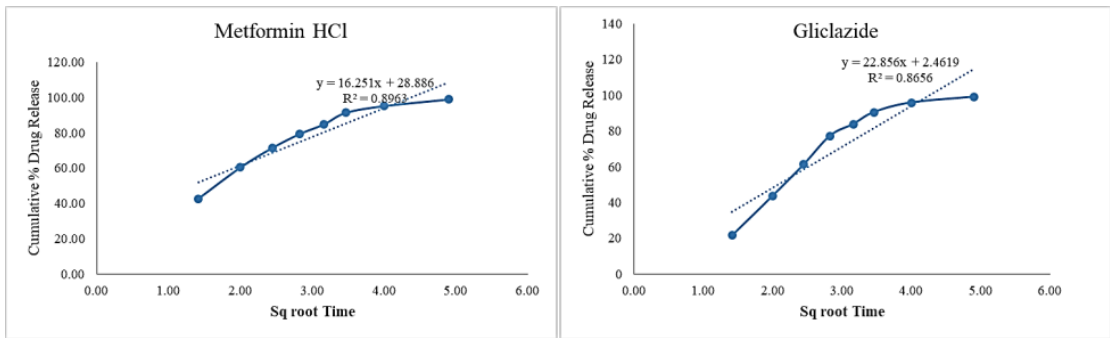

Fig. 9: Higuchi plot of optimized bilayer tablet

The linearity of the Higuchi plot indicates that the release process of metformin hydrochloride and gliclazide from the optimized formulation is diffusion controlled. The Slope values in the Korsmeyer-Peppas equation in fig. 10 indicate that the diffusion mechanism involved was Fickian in the case of metformin hydrochloride and the Non-fickian in the case of Gliclazide in the final bilayer tablet. Thus, the sustained-release bilayer tablet formulation displayed the release of the required quantity of drug with predetermined kinetics to maintain an effective drug plasma concentration. 


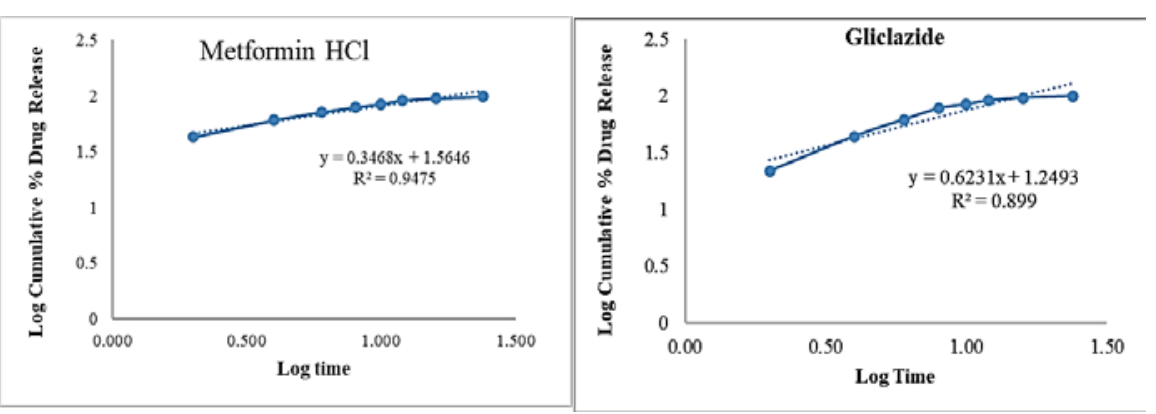

Fig. 10: Korsmeyer-peppas plot of optimized bilayer tablet

\section{Stability studies}

Stability studies of sustained-release bilayer tablets developed in this investigation were carried out for 6 mo in specified conditions. The results reveal that there was no significant change in physical characteristics, \% drug content and \% drug release in $24 \mathrm{~h}$. when stored at $40 \pm 2{ }^{\circ} \mathrm{C} / 75 \pm 5 \% \mathrm{RH}$. Therefore, it has been considered that formulation having good stability.

\section{CONCLUSION}

The monolith diffusion-controlled bilayer tablets of metformin hydrochloride and gliclazide were successfully developed using the lesser concentration of polyox WSR coagulant and HPMC K 100M as retardant polymers respectively. In vitro release profiles revealed that $99.93 \%$ of the metformin hydrochloride and $99.65 \%$ gliclazide were released from the final optimized formulation at the end of $24 \mathrm{~h}$. The drug release follows first order and is diffusion controlled. Therefore, the designed formulation offers improved patient compliance and convenience with better postprandial hyperglycemic control with oncea-day dosing. The sustained release of the drug up to $24 \mathrm{~h}$ regulates antidiabetic activity round the clock with minimal side effects.

\section{ACKNOWLEDGEMENT}

The authors would like to thank the Principal of Andhra University College of Pharmaceutical Sciences for providing their support, facilities, and guidance in this research work.

\section{FUNDING}

Nil

\section{AUTHORS CONTRIBUTIONS}

All authors have contributed equally.

\section{CONFLICT OF INTERESTS}

The authors declare no conflict of interests.

\section{REFERENCES}

1. Goodman LS, Gilman A, Brunton LL, Lazo JS, Parker KL. Goodman and gilman's the pharmacological basis of therapeutics. 12 ${ }^{\text {th }}$ ed. New York: McGraw Hill; 2011.

2. Unnikrishnan R, Anjana RM, Mohan V. Diabetes mellitus and its complications in India. Nat Rev Endocrinol 2016;12:357-70.

3. Rajni J, Piyush J, Poorva J. A review on treatment and prevention of diabetes mellitus. Int J Curr Pharm Res 2016;8:16-8.

4. International Diabetes Federation. Atlas of Diabetes. $5^{\text {th }}$ ed. Belgium: International Diabetes Federation; 2011.

5. World Health Organization Global report on diabetes 2016.

6. International Diabetes Federation, IDF Diabetes Atlas. 8th ed. Brussels, Belgium: International Diabetes Federation; 2017. Available from: http://www.diabetesatlas.org. [Last accessed on 23 Jan 2019]

7. Jadhav VD, Patil JR, Patil PP. Formulation and evaluation of bilayered tablet of piracetam and vinpocetine. J Chem Pharm Res 2011;3:423-31.

8. Shiyani B, Gattani S, Surana S. Formulation and evaluation of bilayer tablet of metoclopramide hydrochloride and ibuprofen. AAPS PharmSciTech 2008;9:818-27.
9. Rashmi MB, Prakash R, Abbulu K, Sudarshan S, Nawres A Taha, Suresh C. Statistical design and development of a liquid oral floating in situ gel of metformin hydrochloride for sustained release: pharmacodynamics and toxicity (histopathology) studies. Int J Appl Pharm 2019;11:96-104.

10. Park K. Controlled drug delivery systems: past forward and future back. J Controlled Release 2014;190:3-8.

11. Al-Omary FA. Gliclazide. Profiles Drug Subst Excipients Relat Methodol 2017;42:125-92.

12. Vishwakarma AG, Pawar AY, Mogal RT. Bilayer tablet-a new ways in oral drug delivery system. Int J Pharm Tech Res 2014;6:1416-28.

13. Lieberman HA, Lachman L. Pharmaceutical dosage form. Vol. 1. New York: 2nd edition CRC Press; 1989.

14. Rahul S Solunke, Uday RB, Krishna M, Madhuri T Deshmukh, Raj Kumar V Shete. Formulation and evaluation of gliclazide nanosponges. Int J Appl Pharm 2019;116:181-9.

15. Wadher KJ, Kakde RB, Umekar MJ. Formulation and evaluation of sustained-release tablets of metformin hydrochloride using hydrophilic synthetic and hydrophobic natural polymers. Indian J Pharm Sci 2011;73:208-15.

16. Purushottam, Gangane $S$, Manish M Kadam, Debarshi KM, Nilesh M, Mahajan U, et al. Design and formulating gliclazide solid dispersion immediate-release layer and metformin sustained release layer in bilayer tablet for the effective postprandial management of diabetes mellitus. Int J Pharm Sci Res 2018;9:3743-56.

17. Nanjwade BG, Manvi FZ. Formulation of extended-release metformin hydrochloride matrix tablets. Trop J Pharm Res 2011;10:375-83.

18. Indian Pharmacopoeia. Vol. 2. New Delhi: Controller of Publication, Govt. of India, Ministry of Health and Family Welfare; 1996. p. 736.

19. Kalpesh W, Sachin K, Kamlesh D Mali, Satish KP, Dheeraj TB. Design and evaluation of bilayer tablets of glimepiride and metformin hydrochloride with the combination of hydrophilic and hydrophobic polymers by hot-melt extrusion of bilayer tablets of glimepiride and metformin. Asian J Pharm Clin Res 2014;7:300-4.

20. Padmaja. Formulation and evaluation of metformin $\mathrm{HCl}$ sustained-release oral matrix tablets. Asian J Pharm Clin Res 2018;11:342-5.

21. Gandhimathi M, Ananda KK, Cheriyan A, Ravi TK. Simultaneous estimation of metformin and gliclazide in tablets using reverse phase high-performance liquid chromatography. Indian J Pharm Sci 2003;65:530-1.

22. Ediga S. A new simple RP-HPLC method for simultaneous estimation of metformin $\mathrm{HCl}$ and gliclazide tablet dosage form. Int J Pharm Biol Sci 2012;2:277-83.

23. Higuchi TA. Mechanism of sustained action medication. J Pharm Sci 1963;52:1145-9.

24. Sudipta D, Arnab S, Himadri SDE. Formulation, in vitro release kinetics and stability interpretation of sustained-release tablets of metformin hydrochloride. Int J Pharm Pharm Sci 2015;7:418-22.

25. Mathews BA. Regulatory aspects of stability testing in Europe. Drug Dev Ind Pharm 1999;25:831-56.

26. Santhosh K, Bhagwat P, Prachi U. Bilayer tablet of tramadol and gabapentin for combination pharmacotherapy of neuropathic pain: development and characterization. Int J Appl Pharm 2018;10:100-7. 